\title{
Annealing Effect on the Optical Properties of a-SiC:H Films Deposited by PECVD*1
}

\author{
Yong-Tak Kim ${ }^{1, * 2}$, Sung-Min Cho ${ }^{1, * 2}$, Byoungyou Hong ${ }^{2}$, Su-Jeong Suh ${ }^{1}$, \\ Gun-Eik Jang ${ }^{3}$ and Dae-Ho Yoon ${ }^{1}$ \\ ${ }^{1}$ Department of Advanced Materials Engineering, Sungkyunkwan University Suwon 440-746, Korea \\ ${ }^{2}$ School of Electrical \& Computer Engineering, Sungkyunkwan University Suwon 440-746, Korea \\ ${ }^{3}$ Department of Materials Science \& Materials Engineering, Chungbuk University Cheongju 361-763, Korea
}

Effects of annealing temperature $\left(T_{\mathrm{a}}\right)$ on the structure of hydrogenated amorphous silicon carbide (a-SiC:H) films prepared by $\mathrm{RF}$ plasma chemical vapor deposition (CVD) method are investigated by using Fourier Transform-Infrared Spectrometry (FT-IR), X-ray Photoelectron Spectroscopy (XPS) and UV-VIS spectrophotometer techniques. It is found that an annealing process results in structural rearrangement and evacuation of hydrogen atoms from $\mathrm{CH}_{n}$ and $\mathrm{SiH}_{n}$ bonds. The emission of hydrogen bonded to silicon and carbon responsible for the decrease of optical band gap $\left(E_{\mathrm{opt}}\right)$ by $0.70 \mathrm{eV}$ in the range of $T_{\mathrm{a}}$ from 573 to $873 \mathrm{~K}$. This hydrogen loss is interpreted in terms of hydrogen molecule formation and outerdiffusion. In addition, the surface morphology of films was investigated by atomic force microscopy (AFM).

(Received September 20, 2001; Accepted June 3, 2002)

Keywords: chemical vapor deposition, silicon carbide (SiC), band gap, annealing

\section{Introduction}

Hydrogenated amorphous silicon carbide (a-SiC:H) films are of great interest owing to their structural electronic, optical and mechanical properties. Indeed, a-SiC:H films are extensively studied both as typical materials of an amorphous system with variable disorder and microstrustures, ${ }^{1-3)}$ and for potential applications such as optoelectronic devices, ${ }^{4)}$ solar cells,${ }^{5)}$ high temperature coatings ${ }^{6)}$ and X-ray masks. ${ }^{7)}$ The main reason for its success in device applications is that by incorporating hydrogen during plasma deposition, the paramagnetic dangling bonds are saturated, ${ }^{8)}$ which reduces the gap state density significantly and makes the n- and p-type doping possible. ${ }^{9)}$ Since the deposition of a-SiC:H does not require high temperature it is essential to examine the thermal stability of the material, which is essentially determined by the bonding states of hydrogen. ${ }^{10)}$ Many phenomena can occur during thermal annealing of a-SiC: $\mathrm{H}$, such as hydrogen emission and structure rearrangement that affect the properties of the amorphous material and its applications, the study of thermal treatment of a-SiC: $\mathrm{H}$ is of great importance.

In this paper, a-SiC:H films are prepared by an RF plasma CVD technique. X-ray photoelectron spectroscopy (XPS) and fourier transform-infrared spectroscopy (FT-IR) technique were used in order to characterize the annealed films qualitatively and quantitatively. The influence of $T_{\mathrm{a}}$ on the optical gap, the bonding state and the amorphous network is investigated by absorption measurements in the ultraviolet to visible (UV-VIS) range, fourier transform-infrared spectroscopy (FT-IR) and atomic force microscopy (AFM), respectively. The $T_{\mathrm{a}}$ range (573-873 K) has been chosen to scan the hydrogen effusion.

${ }^{* 1}$ This Paper was Accepted at the Proceeding of the PRICM4, hold in Honolulu, on Dec. 11-15, 2001.

${ }^{* 2}$ Graduate Student, Sungkyunkwan University.

\section{Experiment}

The a-SiC:H films were deposited onto crystalline silicon and glass substrates using a capacitively coupled RF plasma CVD reactor. The reaction system is of the parallel planar discharge type using a rectangular RF electrode (lower) and substrate electrode (upper). The substrate is set on the tray with the surface to be coated facing downward, so that deposition of dust particles and flakes can be minimized. Hydrogen plasma cleaning at $200 \mathrm{~W}$ for $10 \mathrm{~min}$ was followed directly by the deposition process. The flow rate of hydrogen was $90 \mathrm{sccm}$. All deposition times presented here were $30 \mathrm{~min}$. The full range of process parameters for the system is shown in Table 1.

Annealing of a-SiC: $\mathrm{H}$ films is performed in a furnace of $\mathrm{Ar}$ atmosphere for $3 \mathrm{~h}$ at temperatures ranging from 573 to $873 \mathrm{~K}$. After each annealing step, the XPS measurement was run on a Perkin-Elmer PHI 5700 surface analysis instrument using Mg $\mathrm{K} \alpha \mathrm{X}$-rays (1253.6 eV) as the photoexcitation source with an electron take-off angle of $45^{\circ}$ from the surface. UV-VIS and FT-IR absorption measurements were conducted. Then the $\mathrm{Si}-\mathrm{C}, \mathrm{Si}-\mathrm{H}$ and $\mathrm{C}-\mathrm{H}$ absorption bands were analyzed by plotting the absorption coefficient as a function of radiation frequency using the Lambert-Beer law without any corrections for multiple reflections. The $E_{\text {opt }}$ of the a-SiC:H films was de-

Table 1 Range of deposition parameter for investigation of process parameter effects.

\begin{tabular}{ll}
\hline \multicolumn{1}{c}{ Parameters } & \multicolumn{1}{c}{ Range } \\
\hline Base pressure & $<4 \times 10^{-3} \mathrm{~Pa}$ \\
RF power $(13.56 \mathrm{MHz})$ & $100 \mathrm{~W}$ \\
Substrate temperature & $523 \mathrm{~K}$ \\
Working pressure & $360 \mathrm{~Pa}$ \\
Excitation gas & $\mathrm{H}_{2}(50-100 \mathrm{sccm})$ \\
Reaction gas & $\mathrm{SiH}_{4}: \mathrm{CH}_{4}=1: 1$ \\
\hline
\end{tabular}


posited on a glass substrate using a UV-VIS (Perkin-Elmer) spectrometer in the range of $300-1200 \mathrm{~nm}$. IR vibrational spectra were taken employing fourier transform infrared, (FTIR, Perkin-Elmer 1700) spectrometer. The morphology of film surface was examined by using the contact mode AFM (Multimode SPM Nanoscope III A).

\section{Results and Discussion}

The optical band gap $\left(E_{\mathrm{opt}}\right)$ is estimated from a plot of $(\alpha h v)^{1 / 2}$ vs. $h v$, where $\alpha$ is the optical absorption coefficient, $h$ is Planck's constant and $v$ is the radiation frequency. The optical absorption coefficient, $\alpha$, was calculated from transmittance using the Lambert-Beer law

$$
I=I_{\mathrm{o}} e^{-\alpha \mathrm{d}},
$$

Where $d$ is the film thickness and $I, I_{\mathrm{o}}$ the film, and the substrate transmittance, respectively.

Figure 1 shows the relationship between $E_{\mathrm{opt}}$ and $T_{\mathrm{a}} . E_{\mathrm{opt}}$ decreases slightly for low temperature $(<673 \mathrm{~K})$ annealing as the structure of an amorphous network undergoes relaxation and reordering without any change in the composition or bonding of the atoms. At annealing temperature above $673 \mathrm{~K}$, $E_{\text {opt }}$ decreases significantly indicating the creation of new defect gap states most likely due to the effusion of hydrogen or other species. At temperature above $773 \mathrm{~K}, E_{\text {opt }}$ reaches a saturation value of about $2.1 \mathrm{eV}$. The dependence of $E_{\text {opt }}$ on $T_{\mathrm{a}}$ taking into account that a-SiC: $\mathrm{H}$ films do not crystallize in this range of $T_{\mathrm{a}}$.

Figure 2 shows the transmittance as a function of wavelength for as-deposited and $873 \mathrm{~K}$ annealed films, respectively. The annealed film becomes more transparent than asdeposited film. It has been shown that the absorption is due to transitions from the top of the valence band to the bottom of the conduction band. Increase in density of state in the valence band with increasing in annealing temperatures shifts the absorption edge to lower energies.

Figures 3 and 4 show the FT-IR spectra of a-SiC:H films for investigating the bonding configuration, in the range 400 $4000 \mathrm{~cm}^{-1}$ for various annealed and as-deposited films. It is reported that upon annealing, hydrogen evolves in a twostep process. Which is firstly the breaking of $\mathrm{Si}-\mathrm{H}$ bonds, and then $\mathrm{C}-\mathrm{H}$ bonds, which is justified by the higher $\mathrm{C}-\mathrm{H}$ single bond energy $(98.8 \mathrm{kcal} / \mathrm{mol})$ compared to that of $\mathrm{Si}-\mathrm{H}$ $(70.4 \mathrm{kcal} / \mathrm{mol}){ }^{11)}$ It can be clearly seen that the results shown in Fig. 3 are in good agreement. Intensity of the peaks from 2100 to $2150 \mathrm{~cm}^{-1}$ decrease with increasing annealing temperature, which is due to the break of $\mathrm{Si}-\mathrm{H}$ bonds.

In the Fig. 4, the peaks of about $2900 \mathrm{~cm}^{-1}$ weaken slightly when the temperature is higher than $773 \mathrm{~K}$, which indicates the break of $\mathrm{C}-\mathrm{H}$ bonds in $\mathrm{CH}_{n}$. As discussed before, the emission of hydrogen bonded to silicon and carbon responsible for the decrease of $E_{\text {opt }}$ by $0.70 \mathrm{eV}$ in the range of $T_{\mathrm{a}}$ from 573 to $873 \mathrm{~K}$. The emission of hydrogen bonded to silicon and carbon causes void formation in the a-SiC:H films.

Figure 5 presents the results for the bonding densities of the hydrogen-related modes for different $T_{\mathrm{a}}$. The $\mathrm{Si}-\mathrm{H}$ and $\mathrm{C}-\mathrm{H}$ bonding densities could be estimated from the $\mathrm{SiH}_{n}$ and $\mathrm{CH}_{n}$ stretching mode bonds using the formula

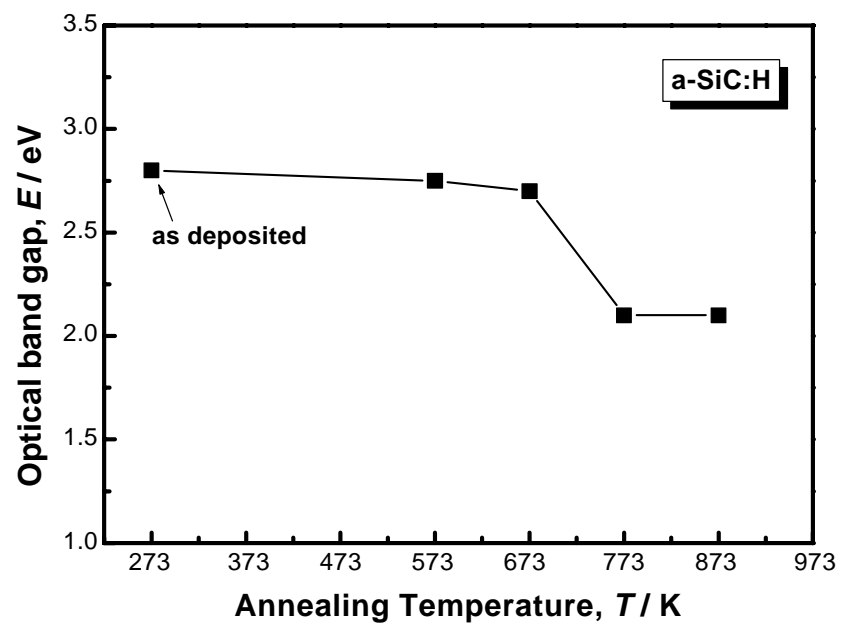

Fig. 1 Relationship between the optical band gap and annealing temperature.

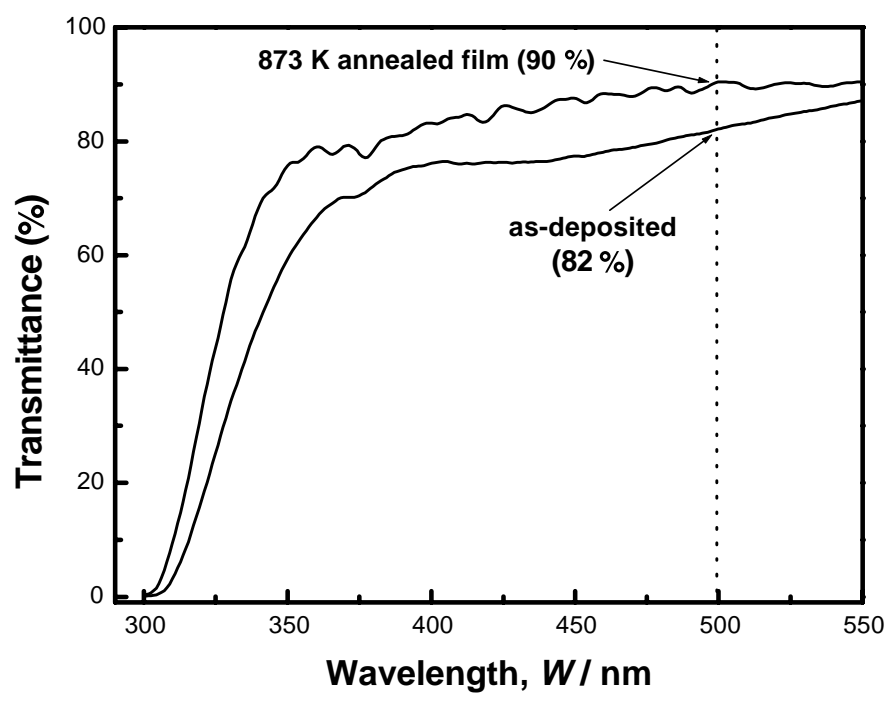

Fig. 2 Optical transmittance of as-deposited and $873 \mathrm{~K}$ annealed film.

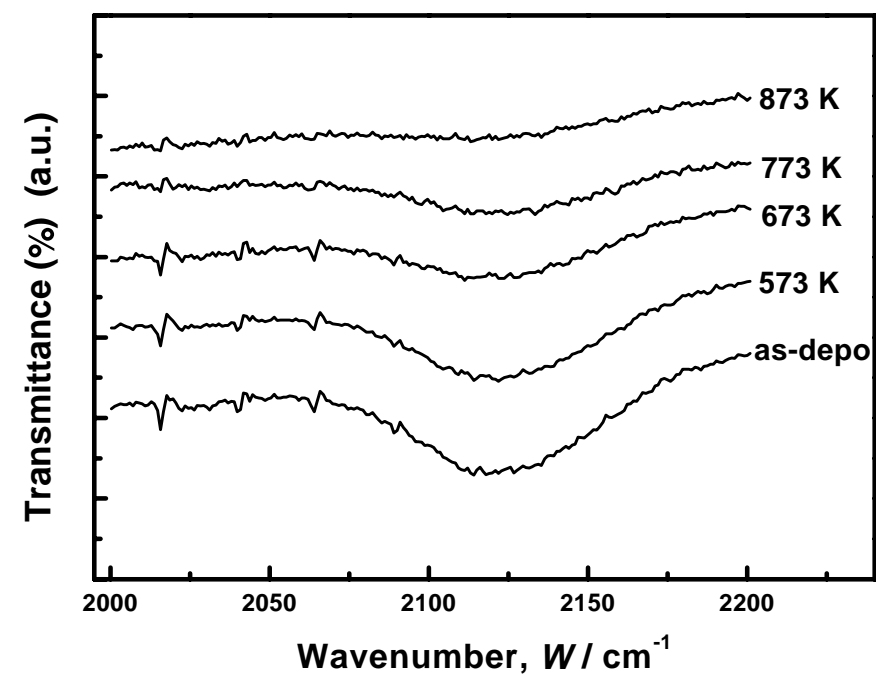

Fig. 3 FT-IR Si-H spectra of the as-deposited and annealed films at various temperature ranging from 573 to $873 \mathrm{~K}$ 


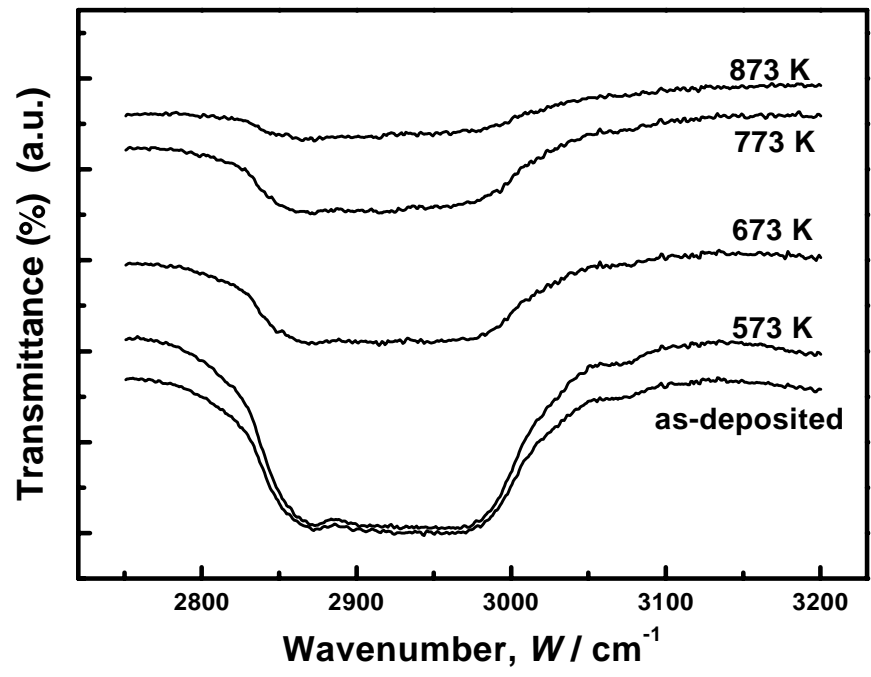

Fig. 4 FT-IR C-H spectra of the as-deposited and annealed films at various temperature ranging from 573 to $873 \mathrm{~K}$.

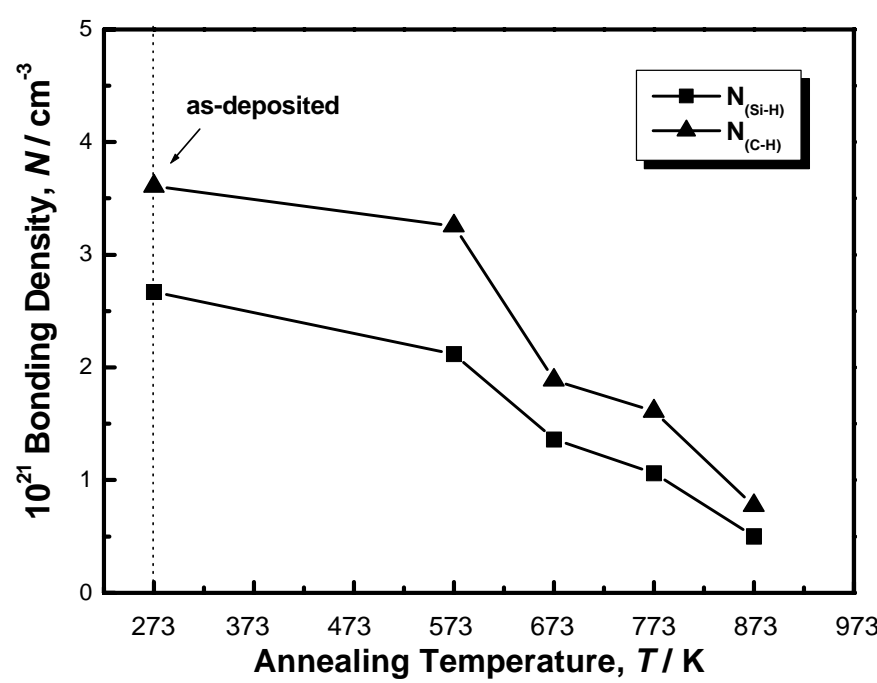

Fig. 5 Bonding density and peak height of $\mathrm{Si}-\mathrm{H}$ and $\mathrm{C}-\mathrm{H}$ vs. $T_{\mathrm{a}}$ for an a-SiC:H films.

$\mathrm{N}($ bonding density $)=A_{\mathrm{s}} \int \frac{\alpha(v)}{v} d v \cong \frac{A_{\mathrm{s}}}{v_{0}} \int \alpha(v) d v$,

where $A_{\mathrm{s}}$ is the reciprocal cross section of a given vibration mode, $v_{0}$ is the center band wave number, $\alpha$ is the absorption coefficient and $v$ is the radiation frequency. The $A_{\mathrm{s}}$ values have been taken from the literature:

$$
\begin{aligned}
& \left.A_{\mathrm{s}}(\mathrm{Si}-\mathrm{H})=1.4 \times 10^{20} \mathrm{~cm}^{-2}, 11\right) \\
& \left.A_{\mathrm{s}}(\mathrm{C}-\mathrm{H})=1.35 \times 10^{21} \mathrm{~cm}^{-2}, 11,12\right)
\end{aligned}
$$

The density of Si-H bonds decreases from $2.67 \times 10^{21} \mathrm{~cm}^{-3}$ for the as-deposited film to $0.303 \times 10^{21} \mathrm{~cm}^{-3}$ for $873 \mathrm{~K}$ annealed film. The density of $\mathrm{C}-\mathrm{H}$ bonds similarly decreases from $3.608 \times 10^{21} \mathrm{~cm}^{-3}$ for the as-deposited film to $0.537 \times$ $10^{21} \mathrm{~cm}^{-3}$ for $873 \mathrm{~K}$ annealed film. The bonding density for $\mathrm{CH}_{n}$ is an order of magnitude higher than for $\mathrm{SiH}_{n}$ indicating that a high concentration of hydrocarbons are incorporated into the film. This seems to suggest that hydrogen may have an affinity for carbon over silicon, as suggested by Gat et al. ${ }^{3)}$ When the $T_{\mathrm{a}}$ is increases, the hydrogen atoms resulting from

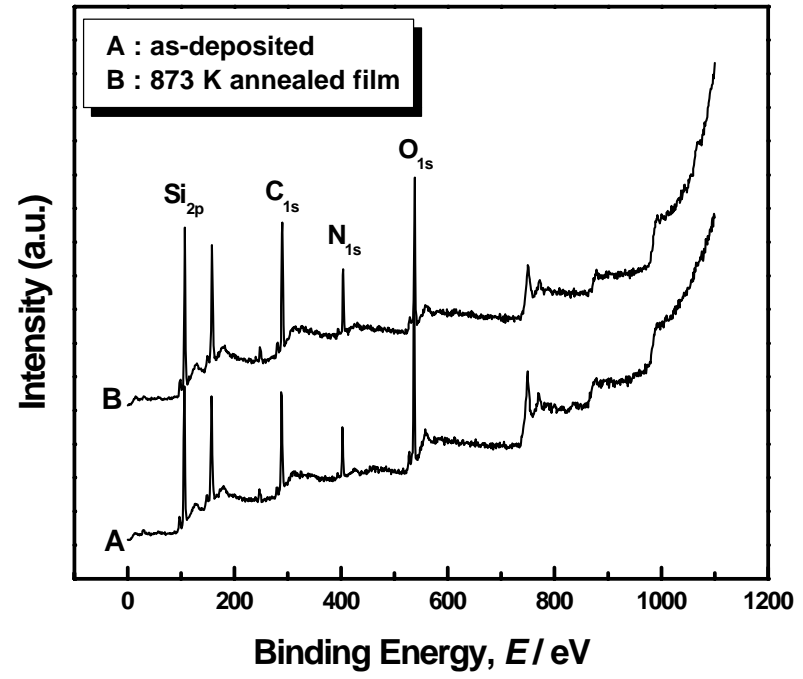

Fig. 6 Wide scan XPS spectra of as-deposited and $873 \mathrm{~K}$ annealed film.

this breaking of hydrogenated bonds can either combine to form hydrogen molecules which are expected to diffuse towards the interfaces during the annealing, or be trapped in the $\mathrm{Si}$ or $\mathrm{C}$ dangling bonds to form new hydrogenated bonds. These observations clearly point out that when the temperature is increased from 573-873 K, both a breaking of hydrogenated bonds resulting in a decrease of hydrogenated bond areas and peak height.

Figure 6 shows the XPS wide scans of the as-deposited and the $873 \mathrm{~K}$ annealed film. Both scans show the silicon $\left(\mathrm{Si}_{2 \mathrm{p}}\right)$, carbon $\left(\mathrm{C}_{1 \mathrm{~s}}\right)$, nitrogen $\left(\mathrm{N}_{1 \mathrm{~s}}\right)$ and oxygen $\left(\mathrm{O}_{1 \mathrm{~s}}\right)$ peaks. After the Ar sputter cleaning treatment, oxygen was found to be still present in films. The oxygen peak was due to absorbed oxygen and surface oxidation of the films. The $\mathrm{Si}_{2 \mathrm{p}}$ component, with binding energy of $(101.8 \pm 0.2) \mathrm{eV}$, was attributed to $\mathrm{Si}$ atoms bonded to oxygen in agreement with $\mathrm{Si}$ oxide contamination in $\mathrm{a}-\mathrm{SiC}: \mathrm{H}$ films. ${ }^{13)}$ The $\mathrm{C}_{1 \mathrm{~s}}$ line peak at $(284.6 \pm 0.2)$ $\mathrm{eV}$ binding energy was attributed to adventitious carbon originating from the residual gas contamination. The carbon contamination peak shifted to about $285 \mathrm{eV}$ for $873 \mathrm{~K}$ annealed film. This is due to additional oxygen contamination. ${ }^{14)}$

The AFM images were acquired by using the contact mode AFM system at room temperature. Figure 7 shows AFM images $(4 \mu \mathrm{m} \times 4 \mu \mathrm{m})$ of the surface morphology of the asdeposited and annealed films at various temperatures, ranging from 573 to $873 \mathrm{~K}$. It is found that the surface morphology of the films is strongly affected by the annealing temperature. The as-deposited film surface was comparatively smooth and the roughness over an area of $4 \mu \mathrm{m} \times 4 \mu \mathrm{m}$ was less than $0.5 \mathrm{~nm}$. After annealing at $873 \mathrm{~K}$ for $3 \mathrm{~h}$, typical protrusions were seen. Root-mean-square (rms) roughness is usually used to evaluate surface morphology because it is the least affected by tip induced distortion of all the roughness parameters. Figure 8 shows the rms-roughness values obtained from AFM images $(4 \mu \mathrm{m} \times 4 \mu \mathrm{m})$. For temperature lower than $573 \mathrm{~K}$, surface roughness is approximately the same as that of the as-deposited film surface. At higher annealing temperature, an increase in roughness (both in the vertical and lateral direction) took place. Above $873 \mathrm{~K}$, this tendency is found to be more obvious. In comparison with the as-deposited film, 
(a)

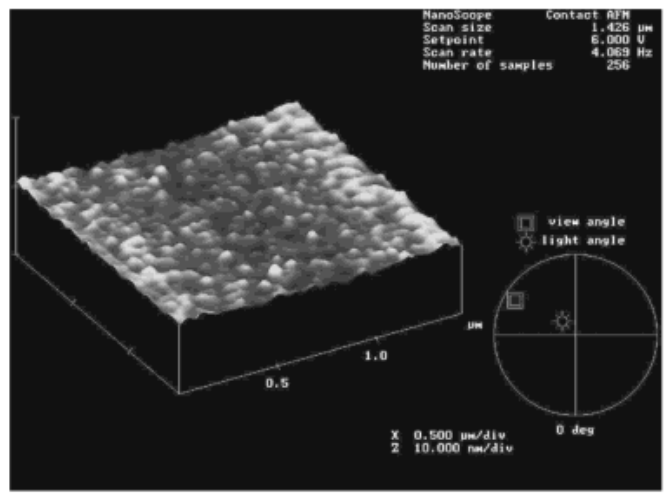

(c)

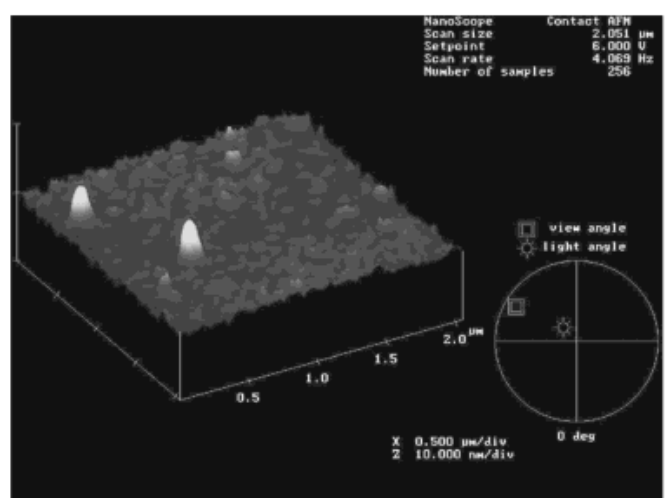

(b)

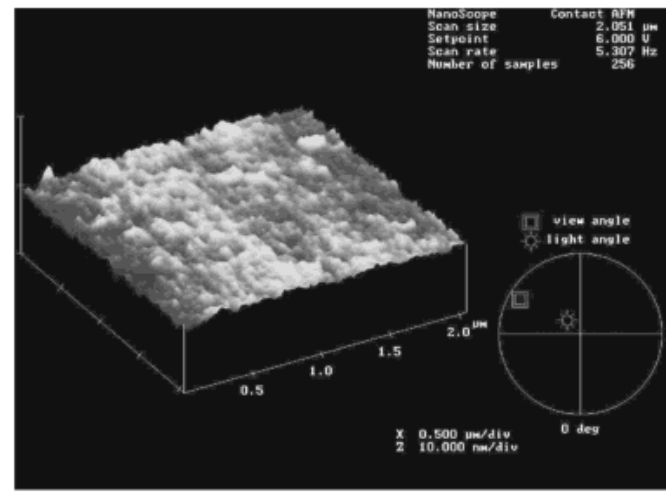

(d)

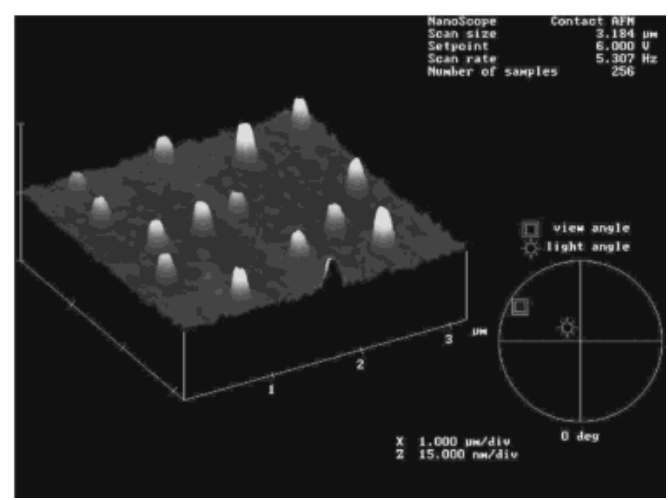

Fig. 7 AFM images of the as-deposited and annealed films at various temperature. (a) as-deposited, (b) $573 \mathrm{~K}$, (c) $773 \mathrm{~K}$, (d) $873 \mathrm{~K}$.

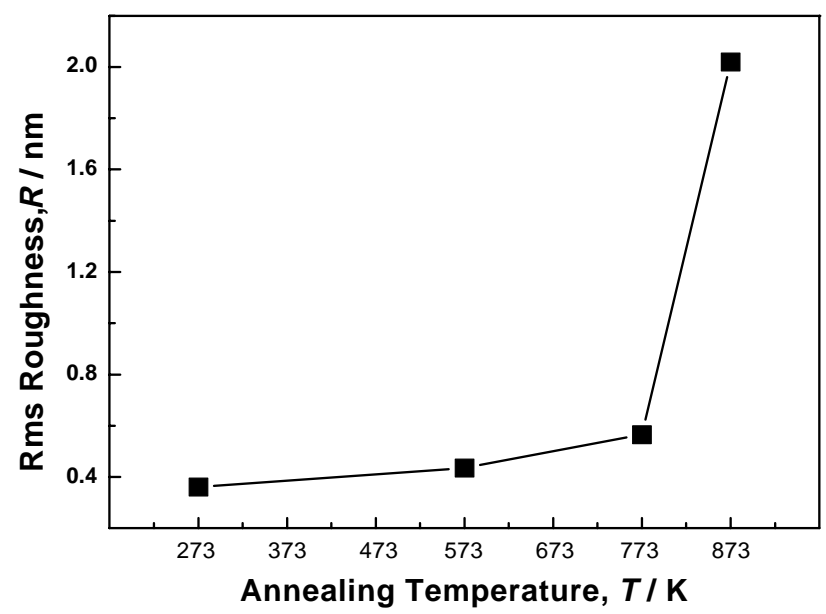

Fig. 8 Rms roughness of the a-SiC:H films as a function of $T_{\mathrm{a}}$.

the rms value increases six times from 0.38 to $2.37 \mathrm{~nm}$. This increase of rms-roughness value is interpreted in terms of hydrogen molecule formation and outerdiffusion. The increasing phenomenon of the rms-roughness value is called "kinetic roughening", ${ }^{15)}$ and is an important parameter for structural and optoelectronic properties.

\section{Conclusion}

The a-SiC:H films deposited by PECVD technique are studied as a function of the $T_{\mathrm{a}}$ in the range from 573 to $873 \mathrm{~K}$.
Using the FT-IR technique, we find a strong correlation between the bonding state of the a-SiC:H film formed and annealing conditions. The annealing indicates the breaking of $\mathrm{Si}-\mathrm{H}$ bonds at first, and then $\mathrm{C}-\mathrm{H}$ bonds at higher temperature. This hydrogen loss is interpreted in terms of hydrogen molecule formation and outerdiffusion. But, hydrogen molecules were not completely outerdiffused and a part of free hydrogen remains trapped in the film. At $T_{\mathrm{a}}$ above $673 \mathrm{~K}$, $E_{\text {opt }}$ decreases significantly indicating the creation of new defect gap states most likely due to the effusion of hydrogen or other species. At $T_{\mathrm{a}}$ above $773 \mathrm{~K}, E_{\mathrm{opt}}$ reaches a saturation value of about $2.1 \mathrm{eV}$. We note a decrease in the $E_{\text {opt }}$ at temperature above $773 \mathrm{~K}$ which indicates an irreversible process and may be mainly attributed to the loss of hydrogen. At higher $T_{\mathrm{a}}$, an increase in roughness took place. Above $873 \mathrm{~K}$, this tendency is found to be more obvious. In comparison with the as-deposited film, the rms value increases six times from 0.38 to $2.37 \mathrm{~nm}$.

\section{REFERENCES}

1) J. Bullot and M. P. Schmidt: Phys. Status. Solidi. B143 (1987) 345-350.

2) Y. Catherine and G. Turban: Thin Solid Films 70 (1980) 101-104.

3) E. Gat, M. A. El Khakani, M. Chaker, A. Jean, S. Boily, H. Pépin, J. C. Kieffer, J. Durand, B. Cros, F. Rousseanx and S. Gujrathi: J. Mater. Res. 7 (1992) 2478-2483.

4) M. P. Schmidt, I. Solomon, H. Tran-Quoc and J. Bullot: J. Non-Cryst. Solids 77/78 (1985) 849-853.

5) Y. Tawada, M. Kondo, H. Okamoto and Y. Hamakawa: Sol. Energy Mater. 6 (1982) 299-302.

6) H. J. Sanders: Chem. Eng. News 62 (1984) 26-31. 
7) A. Heuberger: J. Vac. Sci. Technol. B6 (1988) 107-121.

8) U. Voget-Grote and J. Stuke: J. Electron. Mater. 8 (1979) 749-755.

9) W. E. Spear and P. G. Lecomber: Philos. Mag. 33 (1976) 935-947.

10) T. Friessnegg, M. Boudreau, J. Brown, P. Mascher, P. J. Simpson and W. Puff: J. Appl. Phys. 80 (1996) 2216-2223.

11) K. Mui, D. K. Basa, F. W. Smith and R. Corderman: Phys. Rev. B35 (1987) 8089-8102.

12) A. Guivrac'h, J. Richard, M. Le Contellec, E. Ligeon and J. Fontenille:
J. Appl. Phys. 51 (1980) 2167-2174.

13) K. L. Smith and K. M. Black: J. Vac. Sci. Technol. A2 (1984) 744-747.

14) Y. Mizokawa, K. M. Geib and C. W. Wilmsen: J. Vac. Sci. Technol. A4(3) (1986) 1696-1700.

15) J. Krug and H. Spohn: in Solids Far From the Equilibrium, ed. by C. Grodreche (Cambridge University Press, Cambridge, England, 1991) p. 479. 